Research article

\title{
Synthesis and characterization of copper oxide nanoparticles and its impact on germination of Vigna radiata (L.) R. Wilczek
}

\author{
Ajey Singh, N. B. Singh*, Imtiyaz Hussain, Himani Singh and Vijaya Yadav
}

Plant Physiology Laboratory, Department of Botany, University of Allahabad, Allahabad-211002, U.P, India

*Corresponding Author: singhnb166@gmail.com

[Accepted: 18 June 2017]

\begin{abstract}
Nanoparticles (NPs) and its disposal via anthropogenic activities are a new concern nowadays. The impact of copper on plant metabolism has not yet been studied in detail. In this study, Copper oxide nanoparticles (CuO NPs) were synthesized by wet precipitation method using copper acetate monohydrate precursor. Powder X-ray diffraction, particle size analyzer, scanning electron and transmission electron microscope analysis revealed that synthesized CuO NPs are in nano size range. The impact of synthesized NPs on germination and seedling growth of Vigna radiata were tested. Germination and seedling growth of the plants were almost unaffected at lower concentrations while significant inhibition was recorded at highest $1000 \mathrm{mg} . \mathrm{l}^{-1}$ concentration of NPs as compared to control. Protein and sugar content were used as biochemical parameters to estimate the effects of different concentration of CuO NPs on the metabolism of seedlings. The amount of sugar and protein registered slight higher value at lower concentration and sharply decreased with increase in concentration. By analyzing this compiled information, it is evident that $\mathrm{CuO}$ NPs exhibits a toxic effect on growth and physiology of test plant while at very low concentration effect of NPs may be little favorable also.
\end{abstract}

Keywords: Anthropogenic activities - CuO NPs - Wet precipitation - Biochemical parameters.

[Cite as: Singh A, Singh NB, Hussain I, Singh H \& Yadav V (2017) Synthesis and characterization of copper oxide nanoparticles and its impact on germination of Vigna radiata (L.) R. Wilczek. Tropical Plant Research 4(2): 246-253]

\section{INTRODUCTION}

Nanoparticles (NPs) are natural or anthropogenic materials having at least two dimensions between 1-100 nm. NPs possess numerous distinctive properties like high reactivity, unique optical properties and biocompatibility in comparison to their bulk counterparts due to their very high surface area to volume ratio (Garima et al. 2011). In recent years, nanomaterials (NMs) have contributed in economy of many sectors including consumer products, energy, transportation, cosmetics, pharmaceuticals, antimicrobial agents and agriculture (Singh et al. 2015a). Nanotechnology has tremendous potential to boost agricultural production to fulfill food, fodder and fiber requirements of humans. Use of NPs as fertilizer has a great potential to augment crop yield and diminish environmental threats (Singh et al. 2013, Roohizadeh et al. 2015). On the other hand extensive release of NPs in the environment causing toxicity to the flora and fauna also (Franklin et al. 2007). The hazardous effects of metal oxide NPs can be due to the dissolved ionic metal, or there may be special hazards from NPs themselves due to improved bioactivity. Many authors have pointed out the importance of difference in the toxicity of NPs from heavy metal toxicity (Franklin et al. 2007, Griffitt et al. 2007, Karlsson et al. 2008).

Among the different types of metallic NPs, Copper oxide nanoparticles (CuO NPs) have been mainly used as preliminary material due to its natural abundance, low cost production, non-toxic nature with good electrical and optical properties. Copper $(\mathrm{Cu})$ have position in block D and period four of the periodic table and it is a microelement required for the development of plant. Passam et al. (2007) reported that $\mathrm{Cu}$ in $10^{-14}$ to $10^{-16} \mathrm{M}$ concentrations is required for normal development of plant, below which deficiency occurs however higher concentration than optimum exhibited toxicity. The $\mathrm{Cu}$ deficiency in plants is expressed as curled leaves; 
petioles bent downwards and light chlorosis as well as permanent turgor loss in the young leaves while the higher concentration of $\mathrm{Cu}$ leads to toxicity, growth inhibition, photosynthesis interferences, photo respiration and increases oxidative stress (Yruela 2005, Passam et al. 2007, Manceau et al. 2008). The extensive use of $\mathrm{CuO}$ NPs has increased concerns over their potential toxic impacts on ecosystem and human health due to their discharge from different products to the environment (Chen et al. 2012). Previous reports have revealed that exposure to $\mathrm{CuO}$ NPs caused toxic effects on aquatic organisms such as protozoa, crustaceans, algae, and zebra fish (Nair \& Chung 2014). The effect of $\mathrm{Cu}$ NPs on plant cells has not been studied sufficiently and the available results are uncertain. It has been reported that $\mathrm{Cu}$ is biologically available to mung bean and wheat germs (Lee et al. 2008). Cu exerts its toxic impact by penetrating the cell directly, apparently by causing oxidative damage to cell structures and molecules (Garnett 2007). Cu NPs show positive effects on germination (Shah \& Belozerova 2009) but are phytotoxic at seedling growth (Lee et al. 2008).

Current progress in the field of nanotechnology has guide to the development a new perception of synthesizing nano sized particles of preferred size and shape (Kumar et al. 2015). Synthesis of metal NPs can be accomplished through various methods. Chemical approaches are the most popular methods for the production of NPs. There are several schemes for the synthesis of CuO NPs like precipitation methods, decomposition methods, plasma methods, pulsed wire explosion methods, sol gel methods, vapour deposition, electrochemical, radiolysis methods and so on (Hussain et al. 2016).

The purpose of this study was to synthesize $\mathrm{CuO}$ NPs via wet precipitation method and to analyze specific effect of CuO NPs at different concentration on the germination and growth of Vigna radiata (L.) R. Wilczek as it is one of the most important staple food crops in India.

\section{MATERIALS AND METHODS}

Synthesis of copper oxide nanoparticles

$\mathrm{CuO}$ NPs were synthesized through wet precipitation method (Zhu et al. 2011). Copper acetate monohydrate (99\%), glacial acetic acid (99\%) and sodium hydroxide were used without further purification as they are of analytical grade.

In a typical procedure, about $0.2 \mathrm{M}$ of Copper acetate monohydrate $\left(\mathrm{Cu}\left(\mathrm{CH}_{3} \mathrm{COO}\right)_{2} \cdot \mathrm{H}_{2} \mathrm{O}\right)$ was dissolved in $300 \mathrm{ml}$ of water in round bottomed flask and $1 \mathrm{ml}$ of glacial acetic acid $\left(\mathrm{CH}_{3} \mathrm{COOH}\right)$ was added into that flask and heated to boiling under continuous stirring. After 30 minutes $15 \mathrm{ml}$ of $8 \mathrm{M}$ sodium hydroxide $(\mathrm{NaOH})$ solution was gradually tipped as reducing agent with the help of a needle into the flask. The colour of the solution turned black from blue immediately after addition of $\mathrm{NaOH}$. The reaction was carried out under stirring for $2 \mathrm{hrs,} \mathrm{great} \mathrm{quantity} \mathrm{of} \mathrm{black} \mathrm{precipitate} \mathrm{appeared.} \mathrm{The} \mathrm{mixture} \mathrm{was} \mathrm{cooled} \mathrm{in} \mathrm{room} \mathrm{temperature} \mathrm{and} \mathrm{then}$ centrifuged, obtained wet precipitate was washed twice with DDW to eliminate the impurity. The precipitate was then dried at room temperature for 48 hrs. Brownish black colored powder was obtained and this was carefully collected and stored for characterization.

\section{Characterization of synthesized copper oxide nanoparticles}

First round characterization of the CuO NPs was carried out by X-Ray diffraction (XRD). The XRD pattern of the powdered metal was recorded with the XRD equipment i.e. Rigakud'max 2200 diffracto meter with $\mathrm{Cu}-$ $\mathrm{K} \alpha$ radiation $(\mathrm{k}=1.5406 \AA$ ). Particle size distribution of the $\mathrm{CuO}$ NPs was measured by computer controlled particle size analyzer (Nanotrac wave W3372) to find out the particle size distribution. SEM studies of the synthesized particles were done by JEOLJXA-8230. The synthesized $\mathrm{CuO}$ powder was mixed into DDW and sonicated for $30 \mathrm{~min}$. A tiny drop of the sample was permitted to dry on glass slide to make a thin layer of NPs for the SEM investigation. TEM images were captured on a TECNAI $200 \mathrm{Kv}$ TEM instrument. The nano powders were diluted with DDW and dispersed by ultrasonic bath. Then, one drop was placed on a carboncoated copper grid and left to dry at room temperature.

\section{Germination and seedling vigor index}

Synthesized CuO NPs were suspended directly in DDW and discrete by ultra-sonic vibration for $30 \mathrm{~min}$. The solutions for seed treatments were prepared in five different concentrations: $1 \mathrm{mg} . \mathrm{l}^{-1}, 10 \mathrm{mg} . \mathrm{l}^{-1}, 100 \mathrm{mg} . \mathrm{l}^{-1}, 500$ mg. $\mathrm{l}^{-1}$ and $1000 \mathrm{mg} . \mathrm{l}^{-1}$ and labeled as $\mathrm{Cu} 1, \mathrm{Cu} 2, \mathrm{Cu} 3, \mathrm{Cu} 4$ and $\mathrm{Cu} 5$ respectively. Ten vigna seeds in triplicates were soaked in $20 \mathrm{~mL}$ of respective concentration for 3-4 hrs. The seeds imbibed in DDW only were taken as control and named as $\mathrm{CuC}$. Treated vigna seeds were placed at equal distance in sterilized petriplates lined with Whatman No 1 filter papers. $2 \mathrm{ml}$ of respective concentrations was added in each petriplate. Petriplates were 
covered and kept in a dark place for seven days. Seed germination and seedlings growth were recorded at regular interval of $24 \mathrm{hrs}$. Seedling vigor index (SVI) was calculated by the formula following Abdul-Baki \& Anderson (1973).

$$
\text { Seedling vigor index }=\text { Germination } \% \times(\text { root length }+ \text { shoot length })
$$

\section{Protein and sugar content}

Quantitative analysis of protein was done following Lowry et al. (1951). The quantity of protein was measured with reference to a typical curve of bovine serum albumin. The absorbance was calculated at $650 \mathrm{~nm}$. Total soluble sugars quantification was done by following Hedge \& Hofreiter (1962). The quantity of sugar was determined by the standard curve prepared from glucose. $0.05 \mathrm{mg}$ fresh leaf tissue was homogenized in $5 \mathrm{ml}$ of $95 \%$ ethanol. Following centrifugation, $1 \mathrm{ml}$ of supernatant was thoroughly mixed with $4 \mathrm{ml}$ anthrone reagent and heated for $10 \mathrm{~min}$ in boiling water bath. Following cooling, the absorbance was recorded at $620 \mathrm{~nm}$.

\section{Statistical Analysis}

Treatments were arranged in a randomized block design with three replications. Data were statistically analyzed using ANOVA by using SPSS (Ver.10; SPSS Inc., Chicago, IL, USA). Fitting standard errors of the means $( \pm$ SEM) were calculated for presentation of graphs. The treatment means were evaluated by Duncan's multiple range test (DMRT) at $\mathrm{p}<0.05$.

\section{RESULTS AND DISCUSSION}

Synthesis of copper oxide nanoparticles

The conventional and well known method for synthesis of metallic NPs is wet-chemical procedure. This method involves growing of NPs in a liquid medium having different reactants, in particular reducing agent. The stabilizing agent is also added to the reaction mixture to avoid the agglomeration of NPs (Singh et al. 2016). Colour change of the reaction mixture was observed from deep blue to colour less and then to dark brown on vigorous stirring (Fig. 1). In this process, $\mathrm{CuO}$ produced due to reaction between $\mathrm{Cu}^{++}$ions from copper acetate monohydrate and reducing agents i.e. $\mathrm{NaOH}$. The synthesis process is based on the following chemical reactions:

$$
\begin{aligned}
& \mathrm{Cu}^{2+}+2 \mathrm{NaOH}=\mathrm{Cu}(\mathrm{OH})_{2}+2 \mathrm{Na}^{+} \\
& \mathrm{Cu}(\mathrm{OH})_{2}=\mathrm{CuO}+\mathrm{H}_{2} \mathrm{O}
\end{aligned}
$$

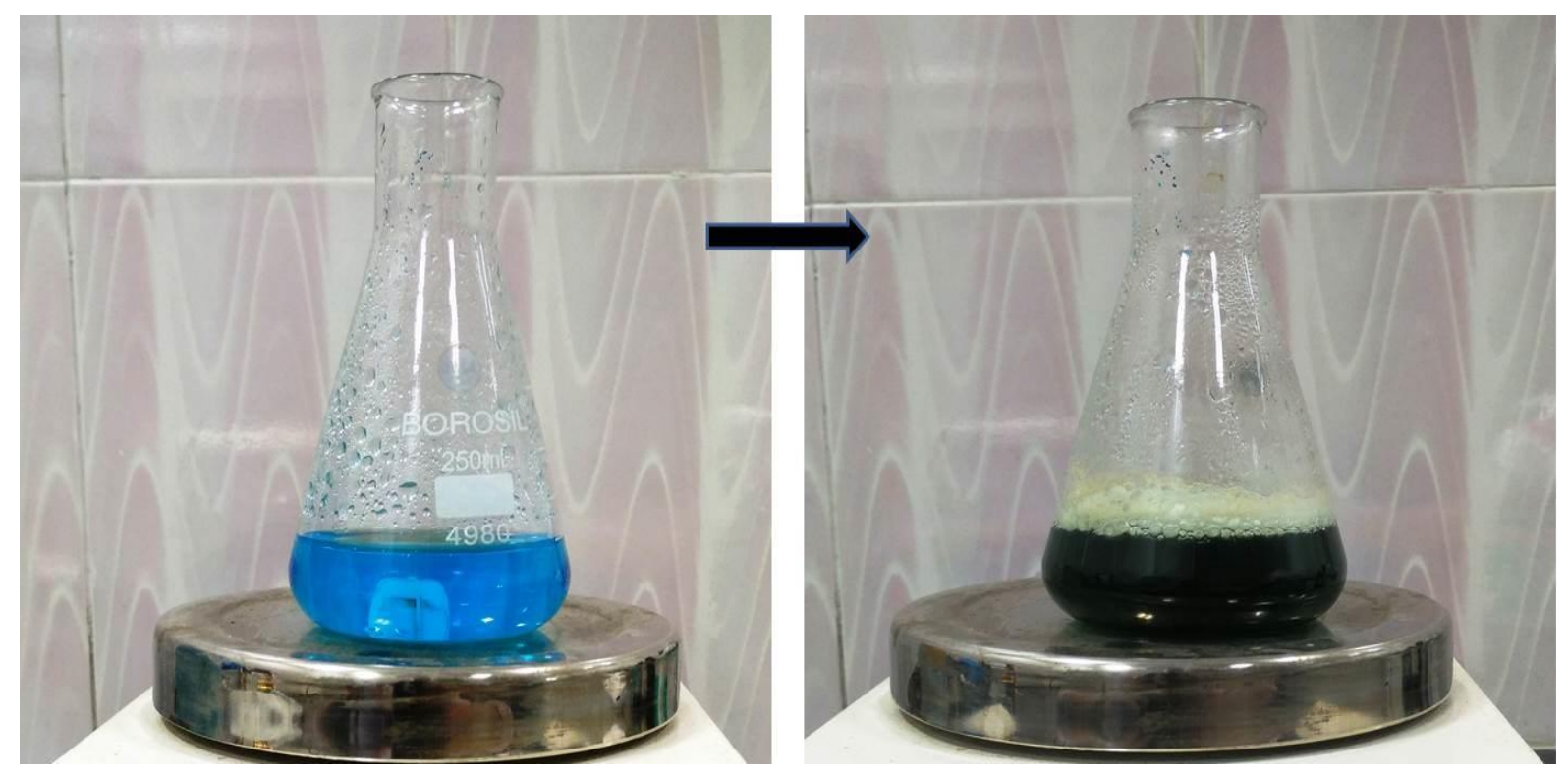

Figure 1. Picture of aqueous solution of $\mathrm{Cu}\left(\mathrm{CH}_{3} \mathrm{COO}\right)_{2} \mathrm{H}_{2} \mathrm{O}$ before adding $\mathrm{NaOH}$ and after addition of $\mathrm{NaOH}$.

\section{Characterizations of copper oxide nanoparticles}

$\mathrm{X}$-ray diffraction (XRD) is recognized as an analytical method for detection and quantitative determination of various crystalline forms which are also known as 'phases' of compound there in powder and solid samples. The XRD technique was used to determine and confirm the crystal structure of the NPs. The XRD patterns of as synthesized $\mathrm{CuO}$ NPs are shown in figure 2(A). The characteristic peaks located at $2 \theta=30.5,38.97^{\circ}$ and 48 . 
$74^{\circ}$ are assigned to (111), (200) and (202) plane orientation of $\mathrm{CuO}$ (JCPDS 80-1268). XRD pattern showed broad diffraction peaks indicating crystalline and nanoscale dimensions of particles. All diffraction peaks can be indexed as typical monoclinic in structure and no other phases were observed.
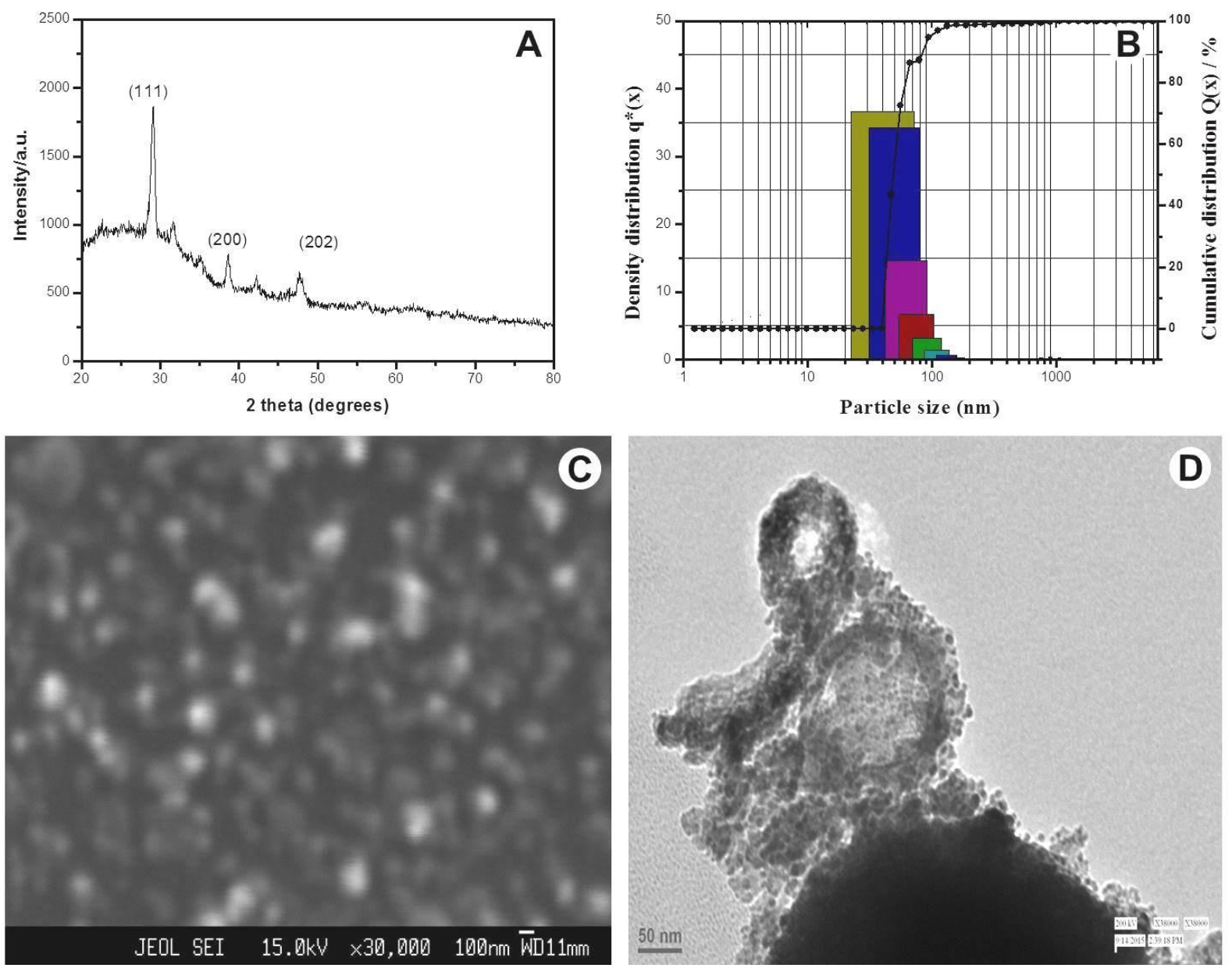

Figure 2. Characterization of synthesized $\mathrm{CuO}$ NPs (A) X-ray diffraction pattern of the synthesized CuO NPs (b) Particle size distribution image of the synthesized $\mathrm{CuO}$ NPs (C) SEM image of the synthesized CuO NPs (D) TEM image of the synthesized NPs.

Dynamic light scattering (DLS) is a method used to decide the size distribution profile of minute particles in suspension or polymers in solution. The size of the particles depends on the size of the size of surface structure, the particle core, concentration of particle and the type of ions in the medium. Particle size analyzer study exposes that the most of the particles in the solution are in range of 35 to $40 \mathrm{~nm}$ (Fig. 2B).

SEM image (Fig. 2C) of CuO NPs demonstrated the presence of some large particles, which can be credited to aggregation or overlapping of smaller particles with sizes around $100 \mathrm{~nm}$. TEM image (Fig. 2D) showed a not well-dispersed and spherical shape for green synthesized CuO NPs with a size range of 20 to 40 $\mathrm{nm}$. The larger particle size is due to the short clusters shown in the TEM image.

It is interesting to note that there is variation in the size of NPs measured with different characterization tools. This can be attributed with the findings of Singh et al. (2016), where authors stated that XRD measures the crystalline size which is smaller than the real particle size while diameter measured using DLS is hydrodynamic diameter of NPs, which is bigger than the actual particle size. In DLS measurement liquid layer moves with NPs during Brownian motion which results in the increased size of NPs than actual size.

\section{Germination and seedling vigor index}

Seed germination was recorded up to 6 days. CuO NPs did not show any toxicological effect on germination up to $500 \mathrm{mg} . \mathrm{l}^{-1}$ concentration. Effect of different concentration of $\mathrm{CuO}$ NPs on seedling growth of Vigna radiata (L.) R. Wilczekis shown in figure 3. However slight enhancement in seed germination was recorded in lower concentrations of NPs i.e. 1 and $10 \mathrm{mg} . \mathrm{l}^{-1}$. Highest concentration i.e. $1000 \mathrm{mg} . \mathrm{l}^{-1}$ of NPs adversely affected the seed germination. Maximum $27 \%$ of inhibition is found in seed germination in seeds treated with 
highest concentration (Fig. 4A). Seed germination is the beginning of the physiological process that needs water imbibitions (Kathiravan et al. 2015). Enhanced seed germination in lower concentration of NPs may be attributed with the findings of Khodakovskaya et al. (2012) as stated that NPs have tendency to penetrate plant seed coats and enhance seed germination and growth. CuO NPs would have penetrated the cell wall and guides new pores formation as a result increase in water absorption which is favorable for seed germination. Germination of lettuce seeds was promoted by Cu NPs (14). In contrast to our result Adhikari et al. (2012) reported that the germination of soybean and chickpea was not checked up to 2,000 ppm concentration of $\mathrm{CuO}$ NPs. Seedling growth and seedling vigor index (SVI) also followed the same trend.

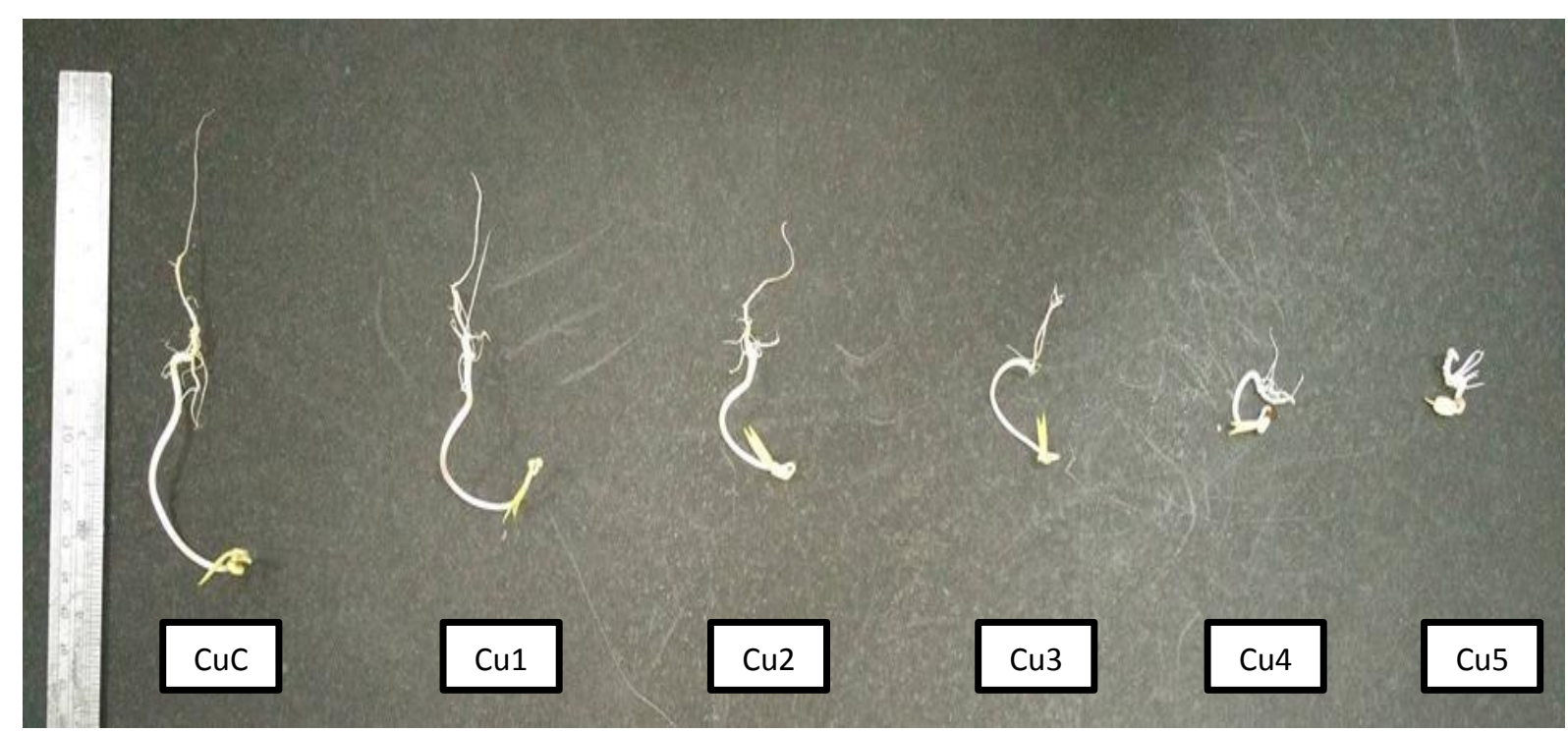

Figure 3. Image showing effect of $\mathrm{CuO}$ NPs on seed germination and seedling growth of Vigna radiata (L.) R. Wilczek seedling. $\mathrm{CuC}=\mathrm{Control} ; \mathrm{Cu} 1\left(1 \mathrm{mg} \cdot \mathrm{l}^{-1}\right) ; \mathrm{Cu} 2\left(10 \mathrm{mgl}{ }^{-1}\right) ; \mathrm{Cu} 3\left(100 \mathrm{mg} \cdot \mathrm{l}^{-1}\right) \mathrm{Cu} 4\left(500 \mathrm{mg} . \mathrm{l}^{-1}\right) ; \mathrm{Cu} 5\left(1000 \mathrm{mg} \cdot \mathrm{l}^{-1}\right)$
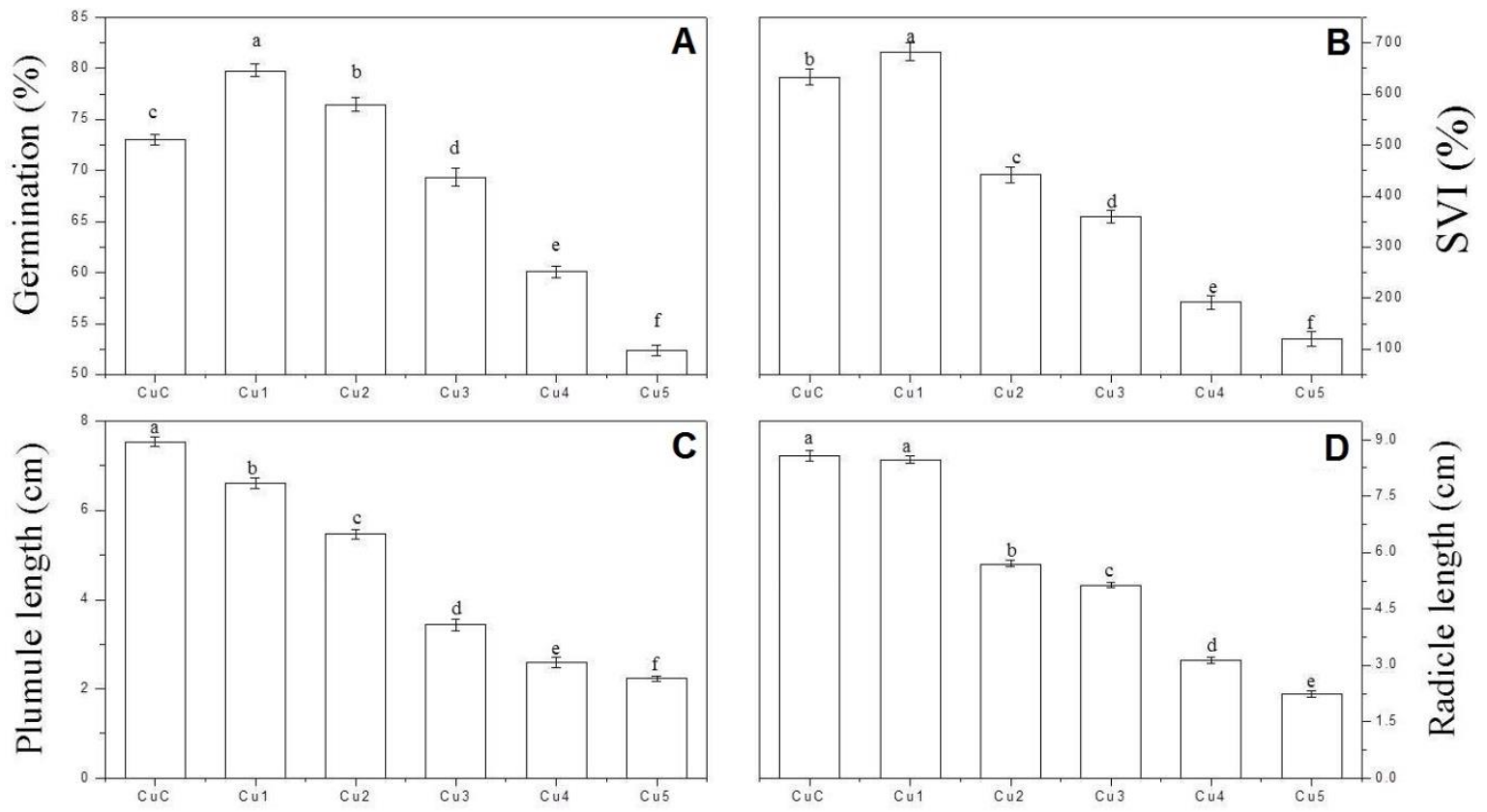

Figure 4. Effect of CuO NPs on (A) seed germination, (B) seedling vigor index (SVI), (C) plumule length and (D) radicle length of Vigna radiata (L.) R. Wilczek seedling. Data are means \pm standard error of three independent experiments with three replicates in each experiment. Bars followed by different letters show significant differences at $\mathrm{p}<0.05$ significance level between treatments according to the Duncan's multiple range test. $\mathrm{CuC}=\mathrm{Control}$; $\mathrm{Cu} 1\left(1 \mathrm{mg} .1^{-1}\right) ; \mathrm{Cu} 2\left(10 \mathrm{mg} . \mathrm{l}^{-1}\right) ; \mathrm{Cu} 3$ (100 mg..$\left.^{-1}\right) \mathrm{Cu} 4$ (500 mg..$\left.^{-1}\right)$; Cu5 (1000 mg..$\left.^{-1}\right)$

Radicle (RL) and plumule length (PL) also followed the germination result. However it is interesting to note that radicle length was found more susceptible to $\mathrm{CuO}$ NPs. There was no promoting effect found in RL at any concentration of NPs however decrease RL was concentration dependent. Declining trend in RL and PL at www.tropicalplantresearch.com 
concentrations higher than $1000 \mathrm{mg} . \mathrm{l}^{-1}$ might be due to more absorption of NPs leading to phytotoxic effects. In this study seed germination was not significantly decreased by NPs because NPs could not pass through seed coats. NPs could contact radicals directly after its emergence through seed coat. Since roots are the first tissue to confront with high concentration of NPs therefore altered growth in radical has dose dependent response. NPs clog with root openings thus nutrient uptake inhibited resulted in decreased plant growth (Adhikari et al. 2012). It was observed that with increase in NPs concentration PL also was found to decline as PL is dependent on the growth and health of radicle. Effect of $\mathrm{CuO}$ NPs seems concentration dependent and higher concentration may be harmful to plants. Maximum inhibition of 74 and $70 \%$ was recorded in RL and PL respectively (Fig. 4). Toxic effects of Cu-NPs in various studies reporting that concentration were higher than $200 \mathrm{ppm}$ (Doshi et al. 2008, Shah \& Belozerova 2009). For mung bean seedling the best growth response for radicle and plumule was observed at lowest concentration. Pätsikkä et al. (2002) and Yruela (2005) stated that elevated concentration of $\mathrm{Cu}$ may injure thylakoid membranes, in that way distressing the functioning of photosystem II and the wateroxidizing complex of chloroplasts. There is $7 \%$ stimulation was recorded in the SVI of the seeds treated with 1 $\mathrm{mg} \mathrm{l}^{-1}$ concentration.

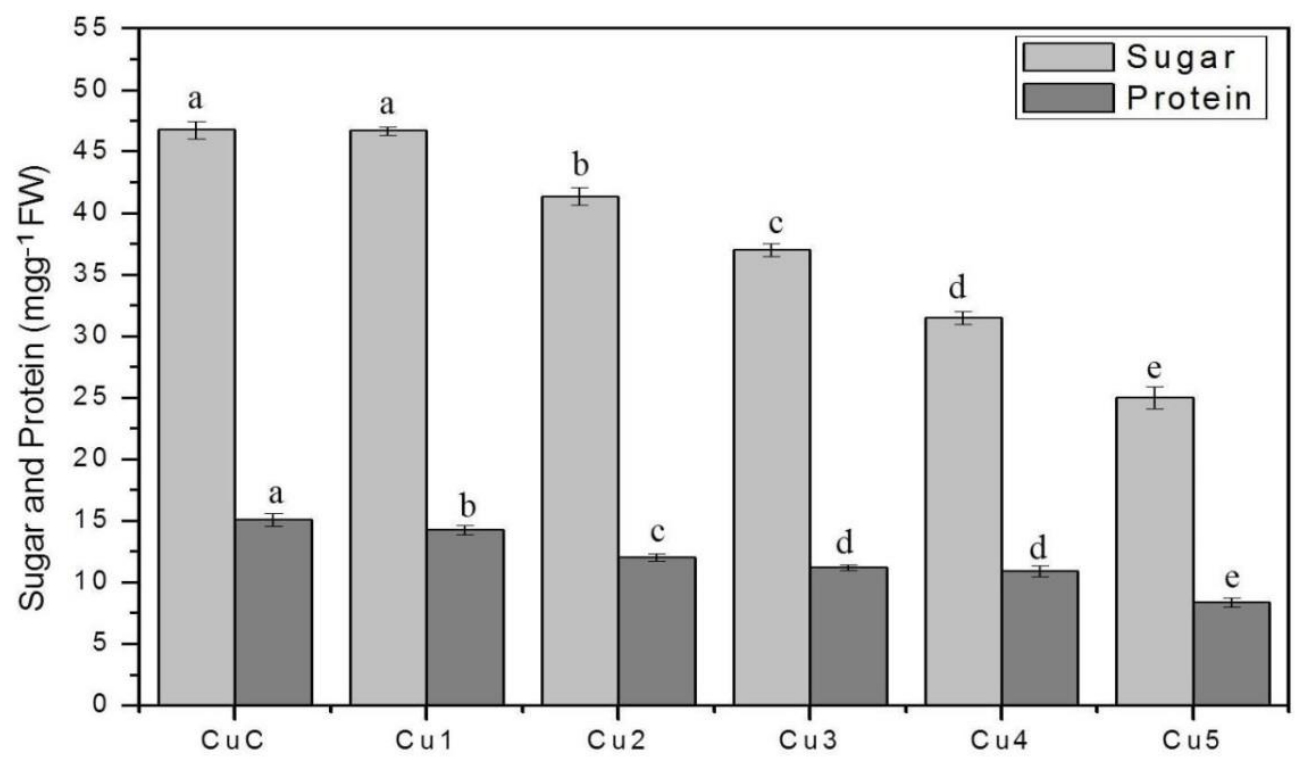

Figure 5. Effect of CuO NPs on sugar and protein content of Vigna radiata (L.) R. Wilczek seedling. Data are means \pm standard error of three independent experiments with three replicates in each experiment. Bars followed by different letters show significant differences at $\mathrm{p}<0.05$ significance level between treatments according to the Duncan's multiple range test. $\mathrm{CuC}=\mathrm{Control} ; \mathrm{Cu} 1\left(1 \mathrm{mg} . \mathrm{l}^{-1}\right) ; \mathrm{Cu} 2\left(10 \mathrm{mg} . \mathrm{l}^{-1}\right) ; \mathrm{Cu} 3\left(100 \mathrm{mg} . \mathrm{l}^{-1}\right) \mathrm{Cu} 4\left(500 \mathrm{mg} . \mathrm{l}^{-1}\right) ; \mathrm{Cu} 5\left(1000 \mathrm{mg} . \mathrm{l}^{-1}\right)$

The increase in $\mathrm{CuO}$ NPs concentrations on vigna seedlings appeared to be negative, primarily due to reduced sugar and protein content. A decrease in sugar and protein under unfavourable conditions allows the conservation of energy, thereby launching the appropriate defense response and also reducing the risk of damage. The protein and sugar content of seedling decreased significantly, reaching the minimum value in the plant treated with $1000 \mathrm{mg} . \mathrm{l}^{-1}$ of CuO NPs (Fig. 5). Maximum inhibition of 44 and $46 \%$ was recorded in protein and sugar content of the seeds treated with highest concentration respectively. Negative effects of $\mathrm{Cu}-\mathrm{NPs}$ on root (Adhikari et al. 2012), seedling growth (Shah \& Belozerova 2009) and shoot growth (Stampoulis et al. 2009) on different plants have been reported. The significant reduction in protein and sugar content might be due to the reduced biomass upon exposure to higher concentrations of $\mathrm{CuO} \mathrm{NPs} \mathrm{or} \mathrm{due} \mathrm{to} \mathrm{the} \mathrm{membrane}$ damage under oxidative stress (Halliwell \& Gutteridge 1989). It has been reported in various studies that metal oxide NPs at their high concentration alters the physiological processes of the plants (Singh et al. 2015b, Hussain et al. 2015).

\section{CONCLUSION}

Heavy use and release of NPs in the environment causing toxic impact on crop plants. Wet precipitation method was found to be very efficient in producing small sized $\mathrm{CuO}$ NPs. The influence of synthesized NPs on germination and seedling growth as well as protein and sugar content of Vigna radiata (L.) R. Wilczek was investigated. The results showed that exposure to higher concentrations of $\mathrm{CuO}$ NPs has resulted in significant 
reduction in the seed germination and caused retardation of seedling growth in test plant. Moreover, exposure to $\mathrm{CuO}$ NPs has resulted in inhibition of protein and sugar content of seedlings which affected plant metabolism. However, it is interesting to note that lower doses of $\mathrm{CuO}$ NPs were found to be not even non-toxic while favoured seed germination, seedling growth and metabolism of the test plant to some extent. $\mathrm{Cu}$ being a micro element is essential for growth and metabolism of plants. Further study is required to explore the minimum and favourable concentrations of $\mathrm{CuO}$ NPs which may be beneficial for plant growth and metabolism to increase the productivity as well as safe release in the environment. Moreover these findings can guide for further investigation of the mechanism of NPs transport within the plant and the potential implications of NPs in the food chain.

\section{ACKNOWLEDGMENTS}

The authors are thankful to the University Grant Commission (UGC), New Delhi, India and University of Allahabad, India for providing financial assistance to Ajey Singh. Dr. Vikas Baranwal, Nanotechnology Application Centre, A.U, Dr. M. Dwivedi, Centre for Petrology and Mineralogy A.U, MNIT, Allahabad and SAIF, AIIMS (New Delhi) are acknowledged for providing XRD, SEM, DLS and TEM facilities respectively.

\section{REFERENCES}

Abdul-Baki AA \& Anderson JD (1973) Vigour determination in soybean seed bymultiple criteria. Crop Science 13(6): 630-633.

Adhikari T, Kundu S, Biswas AK, Tarafdar JC \& Rao AS (2012) Effect of copper oxide nanoparticle on seed germination of selected crops. Journal of Agricultural Science \& Technology 2: 815-823.

Chen Y, Wang D, Zhu X, Zheng X \& Feng L (2012) Long-term effects of copper nanoparticles on wastewater biological nutrient removal and $\mathrm{N}_{2} \mathrm{O}$ generation in the activated sludge process. Environmental Science and Technology 46: 12452-12458.

Doshi R, Braida W, Christodoulatos C, Wazne M \& O'Connor G (2008) Nano-aluminum: transport through sand columns and environmental effects on plants and soil communities. Environmental Research 106(3): 296-303.

Franklin NM, Rogers NJ, Apte SC, Batley GE, Gadd GE \& Casey PS (2007) Comparative toxicity of nanoparticulate $\mathrm{ZnO}$, bulk $\mathrm{ZnO}$, and $\mathrm{ZnCl} 2$ to a freshwater microalga (Pseudokirchneriella subcapitata): the importance of particle solubility. Environmental Science \& Technology 41: 8484-8490.

Garima S, Bhavesh R, Kasariya K, Ranjan AS \& Singh RP (2011) Biosynthesis of silver nanoparticles using Ocimum sanctum (Tulsi) leaf extract and screening its antimicrobial activity. Journal of Nanoparticle Research 13: 2981-2988.

Garnett C (2007) Biodistribution of Nanoparticles: Insights from Drug Delivery. In: Monteiro-Riviere NA \& LangTran C (eds) Nanotoxicoloy: Characterization, Dosing, and Health Effects. Informa Healthcare, New York, USA, pp. 85-98.

Griffitt RJ, Weil R, Hyndman KA, Denslow ND, Powers K, Taylor D \& Barber DS (2007) Exposure to copper nanoparticles causes gill injury and acute lethality in zebra fish (Daniorerio). Environmental Science \& Technology 41: 8178-8186.

Halliwell B \& Gutteridge JMC (1989) Free radicals in biology and medicine, $2^{\text {nd }}$ edition. Clarendon Press, Oxford.

Hedge JE \& Hofreiter BT (1962) Estimation of carbohydrate. In: Whistler RL \& BeMiller JN (eds) Methods in Carbohydrate Chemistry. Academic Press, New York, USA, pp. 17-22.

Hussain I, Singh A, Singh H, Singh SC \& Singh NB (2015) Physiological response of broccoli exposed to $\mathrm{RuO}_{2}$ nanoparticle. Tropical Plant Research 2(3): 246-252.

Hussain I, Singh NB, Singh A, Singh H \& Singh SC (2016) Green synthesis of nanoparticles and its potential application. Biotechnology Letters 34 (4): 245-260.

Karlsson HL, Cronholm P, Gustafsson J \& Moller L (2008) Copper oxide nanoparticles are highly toxic: a comparison between metal oxide nanoparticles and carbon nanotubes. Chemical Research in Toxicology 21: 1726-1732.

Kathiravan V, Ravi S, Kumar SA, Velmurugan S, Elumalai K \& Khatiwada CP (2015) Green synthesis of silver nanoparticles using Croton sparsiflorus Morong leaf extract and their antibacterial and antifungal activities. Spectrochimica Acta Part A: Molecular and Biomolecular Spectroscopy 139: 200-205, 
Khodakovskaya MV, de Silva K, Biris AS, Dervishi E \& Villagarcia H (2012) Carbon nanotubes induce growth enhancement of tobacco cells. ACS Nano letters 6(3): 2128-2135.

Lee W, An Y, Yoon H \& Kweon H (2008) Toxicity and bioavailability of copper nanoparticles to the terrestrial plants mung bean (Phaseolus radiatus) and wheat (Triticum aestivum): Plant agar test for water insoluble nanoparticles. Environmental Toxicology and Chemistry 27(9): 1915-1921.

Lowry OH, Rosebrough RJ, Farr AL \& Randall RJ (1951) Protein measurement with Folin phenol reagent. Journal of Biological Chemistry 193: 265-275.

Manceau A, Nagy KL, Marcus MA, Lanson M, Geoffroy N, Jacquet T \& Kirpichtchikova T (2008) Formation of metallic copper nanoparticles at the soil-root interface. Environmental Science and Technology 1(5): 1766-1772.

Nair PM \& Chung M (2014) Impact of copper oxide nanoparticles exposure on Arabidopsis thaliana growth, root system development, root lignificaion, and molecular level changes. Environmental Science and Pollution Research 21: 12709-12722.

Passam HC, Karapanos IC, Bebeli PJ \& Savvas D (2007) A review of recent research on tomato nutrition, breeding and post-harvest technology with reference to fruit quality. The European Journal of Plant Science and Biotechnology 1(1): 1-21.

Pätsikkä E, Kairavuo M \& Sersen F (2002) Excess copper predisposes photosystem II to photoinhibition in vivo by outcompeting iron and causing decrease in leaf chlorophyll. Plant Physiology 129: 1359-1367.

PPN Kumar Vijay, Shameem U, Pratap Kollu, Kalyani RL \& Pammi SVN (2015) Green synthesis of copper oxide nanoparticles using Aloe vera leaf extract and its antibacterial activity against fish bacterial pathogens. BioNano Science 5: 135-139.

Roohizadeh G, Majd A \& Arbabian S (2015) The effect of sodium silicate and silica nanoparticles on seed germination and some of growth indices in the Vicia faba L. Tropical Plant Research 2(2): 85-89.

Shah V \& Belozerova I (2009) Influence of metal nanoparticles on the soil microbial community and germination of lettuce seed. Water Air and Soil Pollution 197(1-4): 143-148.

Singh A, Singh N.B, Hussain I, Singh H, Yadav V \& Singh SC (2016) Green synthesis of nano zinc oxide and evaluation of its impact on germination and metabolic activity of Solanum lycopersicum. Journal of Biotechnology 233: 84-94.

Singh A, Singh NB, Hussain I, Singh H \& Singh SC (2015a) Plant-nanoparticle interaction: an approach to improve agricultural practices and plant productivity. International Journal of Pharmaceutical Science Invention 4: 25-40.

Singh, NB, Amist N, Yadav K, Singh D, Pandey JK \& Singh SC (2013) Zinc oxide nanoparticles as fertilizer for the germination, growth and metabolism of vegetable crops. Journal of Nanoengineering and Nanomanufacturing 3: 1-12.

Singh, NB, Singh, A, Hussain, I, Singh H \& Singh SC (2015b) Synthesis, characterization and application of ruthenium oxide nanoparticles on growth and metabolism of Brassica oleracea L. Advance Science Letters 21: 2635-2640.

Stampoulis D, Sinha SK \& White JC (2009) Assay-dependent phytotoxicity of nanoparticles to plants. Environmental Science and Technology 43(24): 9473-9479.

Yruela I (2005) Copper in plants. Brazilian Journal of Plant Physiology 17(1): 145-156.

Zhu H, Han D, Meng Z, Wu D \& Zhang C (2011) Preparation and thermal conductivity of CuO nanofluid via a wet chemical method. Nanoscale Research Letters 6: 181. 